\title{
A STANDARD ASSISTED INSTRUCTION SYSTEM IN E-EDUCATION
}

\author{
Gabriel ZAMFIR \\ Bucharest University of Economic Studies, Romania \\ Gabriel.Zamfir@ie.ase.ro
}

\begin{abstract}
Technological developments, determined by the priorities of the society and by the professional competence of the researchers, transformed the environment in an electronic one. Scientific knowledge is creating e-society by integrating standards for hardware as electronic devices. Scientific knowledge becomes e-science once it integrates standards for software applications. At the same time, education evolves to e-education, as soon as integrates standards systems for teaching and learning. This paper synthesizes the main features of the eeducation, determined by the e-society requirements and the e-science techniques, and it describes a solution developed as a standard assisted instruction system in e-education, in the terms of the functionalities of a teaching-learning system.
\end{abstract}

Keywords: assisted instruction system, e-education principles, e-society standards, learner's cognitive system, teaching and learning system

JEL classification: I23

DOI: $10.12948 / \mathrm{ie} 2019.04 .01$

\section{Introduction}

E-society is a valuable concept when we structure the educational resources of the environment generated by the technological developments. Three categories are already available for a standard user analyze. The first one, the electronic resources represent the traditional resources, projected in the new context, for example, all printed books, scanned, stored, and available in electronic format. The second one, the digital resources, they are new, for example, the digital services, designed in order to purchase a ticket for a flight. The third one, the virtual resources, reflects an augmented reality, for example, a visit in a virtual museum. This approach dedicated to the concept $e$-society explains how the three forms of the traditional education: formal, nonformal, and informal education, all of them growths in the same electronic new context.

As soon as our analyze highlights learning, as a basic activity of the human development, we mention here the three paradigms of learning in e-society, as they describe the concept in [1]: a lexical paradigm, a terminological paradigm, and a conceptual paradigm, three levels of understanding of the same process. The explanation of such a phenomena is because the character of human reasoning which it was different during various stages of the development of a human cognitive system. For example, in [2], based on reviews of pioneering work within smart learning, smart education, and smart learning environments, the authors highlight two models, a cognitive smart learning model, and a smartness level model. These models are evaluated against current standardization challenges in the field of learning, education and training to form the basis for a development platform for new standards in this area. Another example is [3]; in this paper, smart learning environments are defined as physical environments that are enriched with digital, context-aware, and adaptive devices, to promote better and faster learning. In order to identify the requirements for 'better and faster learning', the idea of Human Learning Interfaces is presented, i.e. the set of learning related interaction mechanisms that humans expose to the outside world that can be used to control, stimulate and facilitate their learning processes. Papers highlighting standards for smart education, smart learning 
environments, and even smart learning, propose descriptive metaphors, and all of these phrases refer to the lexical paradigm. One-step to an explanatory metaphor is smart education framework. In [4] the authors describe the three essential elements in a technology-facilitated smart education environment, which are teaching presence, technological presence, and learner presence. Both the instructor and students share the teaching presence. It describes the teaching role in a smart education system as instructional design, facilitation and direct instruction, and technological support. The learner presence consists of learners' competency to being autonomous and collaborative learners as well as efficient users of technologies. The technological presence concerns to what extent technologies can create connectivity, provide ubiquitous access to learning resources, and adapt to personal needs. The technological presence provides a foundation for learning to occur. Such an approach is necessary when we work for cognitive development of the learner, which it has a tendency to finalize as a cognitive autonomous system.

\section{Conceptual framework}

Scientific research is a methodological investigation of a scientific subject of a particular domain for adding to knowledge, as a theoretical approach, and verified in a case study, as a practical approach. The scientific progress integrates the equilibrium between methods (defined as theoretical approaches) and techniques (defined as practical approaches). In fact, we develop the methodological approach based on concepts map, presented in [1], which mentions the desktop-fieldwork paradigm, as a base of a threefold actions of learning: knowledge, understand and application, in order to configure a user cognitive infrastructure. The building blocks of an e-education framework implies two others infrastructures: the technological one and the conceptual one, as we observe in [5]. Therefore, the methodological approach based on concepts map in e-education shows the functional update in Figure 1.

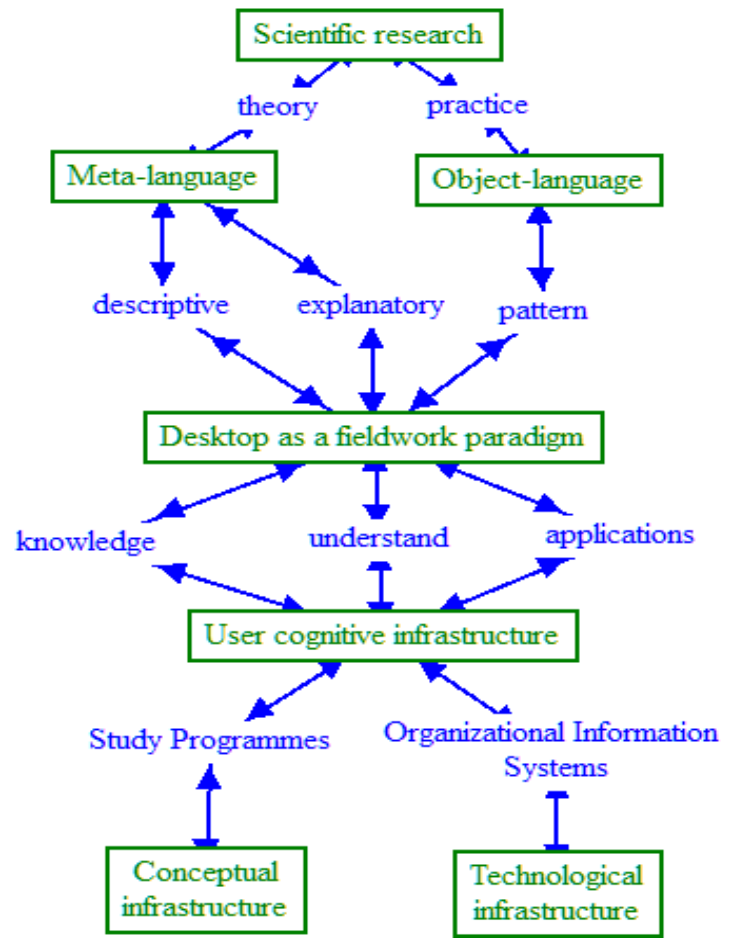

Figure 1. Methodological approach based on concepts map in e-education

The main features of an e-education system are the global functionality and the diversity of the users. The technological infrastructure presumes different levels of the information systems 
(home-based, institutional, metropolitan, national, regional, and global) while the conceptual infrastructure assumes study programs based on curriculum, subjects, syllabuses and concepts map. The central point of this new approach and the main feature of the e-education context is consisted of the desktop as a fieldwork paradigm; the phrase is a general one of another three already classical metaphors for the desktop: school desk, master desk, and desk or table. It is essential to differentiate these three metaphors, which are descriptive metaphors, comparing with the desktop as a fieldwork, which is an explanatory metaphor. One more example for a descriptive metaphor is the typewriter assuming for a word processor, which highlights a limited comprehension of a new concept according to a descriptive metaphor, and not to an explanatory one, like the word processor - an instruction environment for processing a research project.

Such kind of approach focuses on the user cognitive infrastructure, defined as the environment of the cognitive development of the student, in order to create a cognitive system for the user. Desktop as a fieldwork paradigm is the base for metacognitive development, being a construct, which presumes, at the same time, a meta-language, and an object language.

\section{Theoretical framework}

Using the concept of e-society as an explanatory metaphor, educational laboratory, we understand that e-education includes the traditional education, and it is evolving based on its particularities, technological infrastructure, and conceptual infrastructure.

Based on the building blocks of the scientific research (ontology, epistemology, methodology, and methods) and on the interrelationships between the building blocks of assisted instruction in e-education, developed in [6], we create a theoretical framework, dedicated as a base for initiating an operational assisted instruction system in e-education; see the image presented in Figure 2.

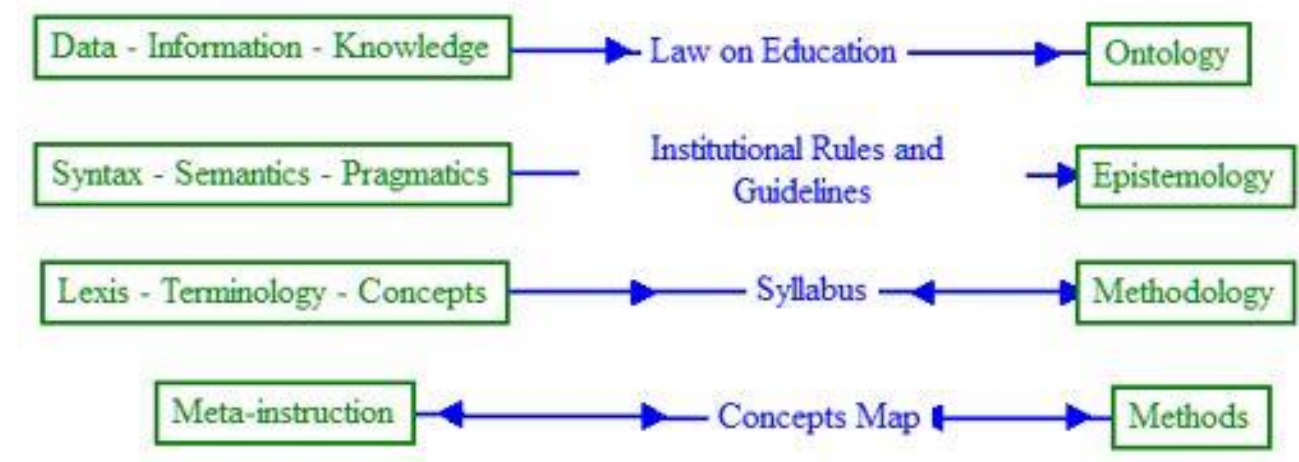

Figure 2. Theoretical framework based on assisted instruction in e-education

In our educational laboratory, we can find guidelines developed to assist countries wishing to assess the compatibility of their national education laws and policies with international standard-setting instruments on the right to education [7]. In Romania, the traditional education system depends on Law on Education. Law on Education [8] consists of 365 articles, structured in titles, chapters, and sections; there were operated 76 updates during eight years. The third article consists of 21 principles. The law regulates a complex and dynamic context, in order to shape the human personality. Each higher education institution elaborate rules and guidelines for didactic activity, based on Law on Education. Each discipline has a syllabus, consisting of estimated total time, prerequisites, conditions, acquired specific competences, objectives, and content, mentioning teaching work methods, and recommendations for students. The final 
section is about assessment: criteria, methods and the final grade. Integrating the traditional class, as course and seminar, in a laboratory activity, we develop the e-education system, as an extension of the traditional education system, in order to assimilate the new concepts in the Law on Education.

Using the concept $e$-society defined as a society of the systems, [5] highlights the main teachinglearning systems in e-education, which depend on time and space: T-Class (different places, the same time), P-Class (different time, the same place), e-Class or virtual-Classroom (different places and different time), and e-Classroom (the extension of the traditional classroom, the same time, and the same place). The e-Classroom, which integrates assisted instruction, consisting of computer-assisted instruction and teacher assisted learning, presumes principles, as any other human activity. The same principles reveal the foundations for of any software application or service of an e-education system.

In e-education, individualized educational activities represents the first principle, and this is the first characteristic of a standard $e$-Classroom. The second principle descends from the first one: personalized learning integrates the student-own-pace concept. Cognitive interactivity defines the functionalities of a learning system in e-education. Based on the triple-vision of the personal computer as tool, tutor, and tutee, the third principle depends on the adequate information granularity of the electronic, digital, or virtual content. This third principle of the e-education progresses in a concept map approach. Two more principles use technology developments as a meta-discipline: while it integrates interdisciplinary approaches because of the diversity as forms of knowing and transdisciplinary approaches because of the diversity as forms of knowledge. These five principles presented in [9] need refinements in a systemic vision. Developing computer literacy as a meta-discipline consists the basis of the sixth principle of the e-education: self-control of learning through self-assessment.

\section{Analytical framework}

Developing computer literacy as a meta-discipline consists the foundation for creating, using and versioning educational software, too. 32 years ago [10], in the ninth chapter, Problems and promises, in the section The Future, at page 284, it contains the authors' idea: "As a result of the expanded capabilities of technology, teachers will have different functions than they do today. They will spend more time attending to the needs of individual students and less time worrying about class norms. They will be relieved of tedious nonteaching task such a maintaining attendance and performance records; and they will become the skilled managers of complex instructional systems that bear little resemblance to today's classrooms." This point of view is understandable correlated with the fact that in 1958, the United States was the first country to study computer-assisted instruction, while a comparative analysis shows that there is still a wide gap in this field due to the poor universality of relevant software, which has restricted its widespread application in the education industry [11].

The previous researches focused on e-classroom and on the main components of a teachinglearning system, revealed two phrases already classics: Computer Assisted Instruction and Teacher Assisted Learning. They are useful components in the theoretical framework section presented in [12]. This approach reflects e-Classroom as an extension of the traditional classroom, because face-to-face teaching, learning, and assessing are included; at the same time, it confirms that the prefix "e" from electronic could be apply to an information system but not to an activity based on human thinking.

New services, presumed by an information system are included, such as intranet-personalized services, intranet customizable services, web customizable services and web personalized services. The web services create a connection with the e-classroom from home, for example. All the activities, projects, and instructional applications are available and workable at home. 
www.conferenceie.ase.ro

Computer Assisted Instruction presumes with two types of components: standard assisted individual studies and standard assisted instruction applications. They are labelled as standard as soon as they are permanent updated based on the track and on the feedback mechanisms integrated by the Teaching Assisted Learning component. Assisted instruction applications review the basic concepts, the aggregate concepts, and the threshold concepts of a fieldwork, while assisted individual studies review models, methodologies and theories of the same fieldwork. First class of techniques focus on knowledge, comprehension and application, while the second class focus on analysis, synthesis and evaluation, as they are the six levels of the Bloom's taxonomy, used in the paradigm of meta-instruction. Therefore, the standard functionalities for an assisted instruction system in e-Classroom, as one of the fourth teachinglearning standards systems in e-education, reflects the new context in the image in Figure 3.

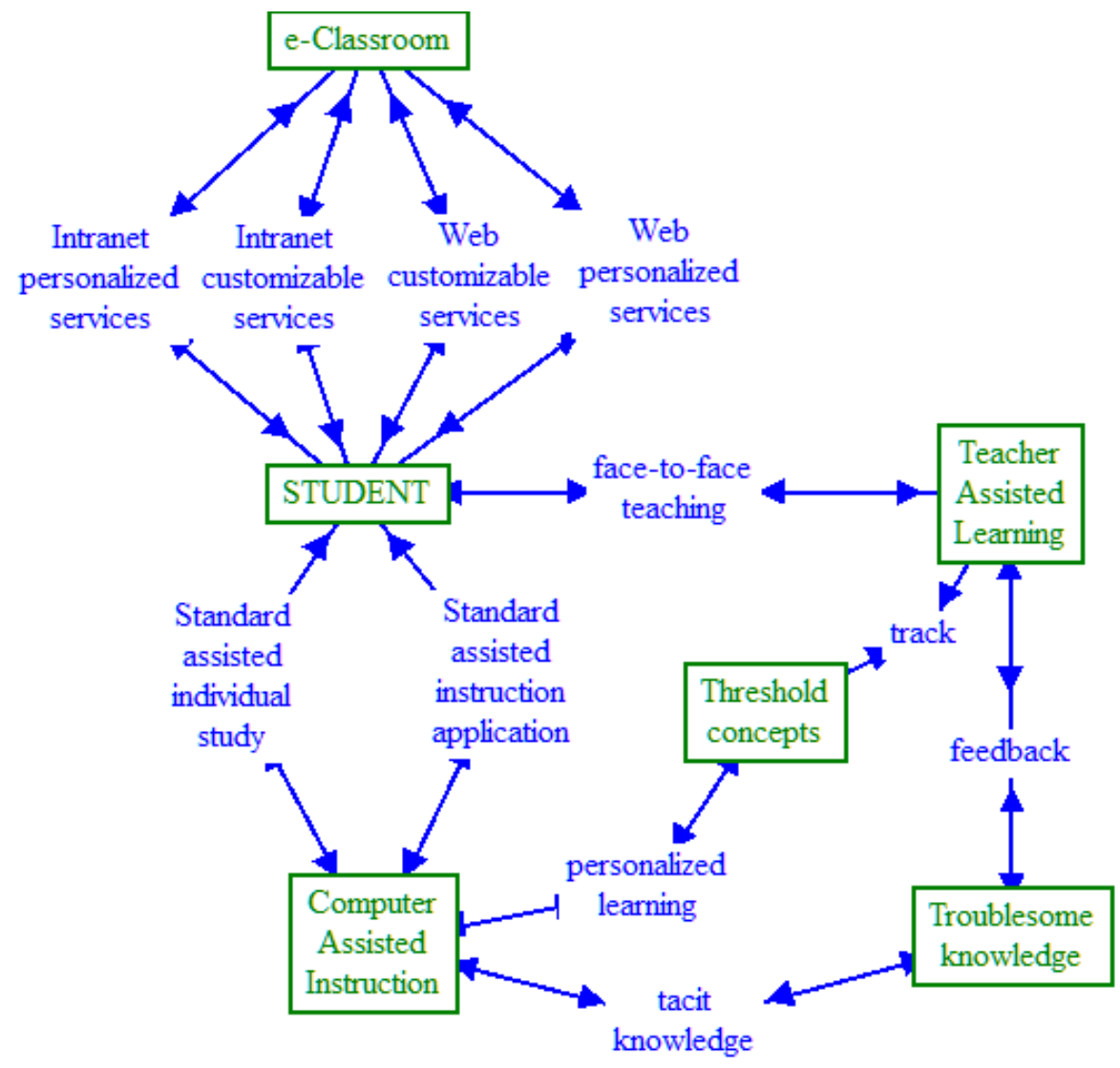

Figure 3. Standard functionalities for an assisted instruction system in e-Classroom

This structure highlights two key elements of a face-to-face teaching-learning system, referring to personalized learning and tacit knowledge as two basic components of the student's cognitive system. The personal computers support them as tool, tutor, and tutee. The teachers explain the context and sustain upgrade as new versions for assisted studies and applications.

\section{Conclusions}

Developing and experimenting an assisted instruction system in e-education presume Just-InTime Teaching and Learning activities knowledge, comprehension, and application, then analysis, synthesis, and evaluation. Optimizing such an instruction process depends on two basic methodological factors: one is the support for a descriptive approach, and the other is the sustenance of an explanatory approach. The teacher assures the most relevant functionality of 
such standard assisted instruction system, as he is responsible for optimizing personalized learning and tacit knowledge of the student. At the same time, the teacher develops the support and functionalities of the standard assisted individual study and of the standard assisted instruction applications as new versions, based on track and feedback of the assisted instruction system. Such an assisted instruction system, as a general solution, reflects a framework for the recursive process in forming professionals and for the iterative process in developing new versions for e-classroom.

\section{References}

[1] G. Zamfir, "Learning Paradigms in e-Society," Informatica Economica, vol. 17, no. 3, 2013, pp. 99-113, https://doi.org/10.12948/issn14531305/17.3.2013.09

[2] T. Hoel, J. Mason, "Standards for smart education - towards a development framework," Smart Learning Environments, vol. 5, 2018, Springer Open, https://doi.org/10.1186/s40561-018-0052-3

[3] R. Koper, "Conditions for effective smart learning environments," Smart Learning Environments, vol. 1, 2014, Springer Open, http://www.slejournal.com/content/1/1/5

[4] Z. Zhu, Y. Sun, P. Riezebos, "Introducing the smart education framework: core elements for successful learning in a digital world," International Journal of Smart Technology and Learning, vol. 1, no. 1, 2016, InderScience Publishers, https://www.inderscience.com/info/inarticle.php?artid=78159

[5] G. Zamfir, "Assisted Learning Systems in e-Education," Informatica Economica, vol. 18, no. 3, 2014, pp. 91-102, https://doi.org/10.12948/issn14531305/18.3.2014.08;

[6] G. Zamfir, "Learning Support for Standard e-Classroom," Informatica Economica, vol. 19, no. 3, 2015, pp. 46-58, https://doi.org/10.12948/issn14531305/19.3.2015.04;

[7] UNESCO, "The Right to Education, Law and Policy Review Guidelines," published in 2014 by the United Nations Educational, Scientific and Cultural Organization, ED2014/WS/18, https://unesdoc.unesco.org/ark:/48223/pf0000228491

[8] *** - The Law No. 1 of 5 January 2011 - Law on education -, published in the Official Journal of Romania, Part I, No. 18 of 10 January 2011

[9] G. Zamfir, "Dual applications for metacognitive development in assisted instruction," Informatica Economica, vol. 21, no. 2, 2017, pp. 54-67, https://doi.org/10.12948/issn14531305/21.2.2017.05;

[10] R. V. Bullough SR., L. F. Beatty, "Classroom Applications of Microcomputers," Columbus: Merrill Publishing Company, 1987, pp. 342.

[11] H. Guo, "Application of a Computer-Assisted Instruction System Based on Constructivism," iJET International Journal of Emerging Technologies in Learning, vol. 13, no. 4, 2018, https://online-journals.org/index.php/i-jet/article/view/8468

[12] G. Zamfir, "Concepts Map Approach in e-Classroom," Informatica Economica, vol. 16, no. 3, 2012, pp. 124-135, http://www.revistaie.ase.ro/content/63/11\%20-\%20Zamfir.pdf 